Check for updates

Cite this: Chem. Commun., 2022, 58,1728

Received 12th November 2021 Accepted 6th January 2022

DOI: $10.1039 / \mathrm{d} 1 \mathrm{cc} 06398 \mathrm{~g}$

rsc.li/chemcomm

\section{Concurrent base and silver(I) catalysis pulsed by fuel acid $\dagger$}

\author{
Isa Valiyev, (D) $\ddagger$ Amit Ghosh, $\ddagger$ Indrajit Paul and Michael Schmittel (D) *
}

\begin{abstract}
Treatment of a crown-ether receptor and a silver(l)-loaded cyclam derivative ( NetState-l) with a fuel acid reversibly afforded the protonated cyclam and the silver(I)-loaded crown ether (=NetState-II). While NetState-I was catalytically OFF, a base-catalysed Michael addition and a silver(I)-catalysed oxime cyclisation reaction was pulsed under dissipative conditions in NetState-II.
\end{abstract}

Multicellular organisms maintain life out of equilibrium through autonomous chemical networks that involve information handling ${ }^{1}$ and storage ${ }^{2}$ as well as energy transfer. ${ }^{3}$ In order to advance autonomy in artificial systems ${ }^{4}$ or precise control in the time domain, ${ }^{5}$ it is desirable to interconnect (by chemical communication) molecular ensembles and to operate them under dissipative conditions. Implementation of the time domain has recently stimulated the development of chemically fuelled systems. ${ }^{6-8}$ Based on fuel, a handful of systems involving either molecular communication, ${ }^{9,10}$ or catalysis have become known, ${ }^{11,12}$ however, dissipatively pulsed catalysis within a communicating network is unprecedented.

Building on communication protocols involving metal-ion pulsing, ${ }^{13}$ we demonstrate a fully reversible system with (i) fast signalling between interdependent components that allows (ii) concurrent orthogonal double catalysis, all under dissipative conditions. The design was based on two well-defined networked states (NetStates). NetState-I encompasses the anthracene-appended cyclam 1, the anthracene-appended azacrown ether 2 and silver(I) ions in 1:1:1 ratio (Scheme 1) and requires an incomplete self-sorting ${ }^{14}$ affording $[\mathrm{Ag}(\mathbf{1})]^{+}$and free 2. Upon acid addition, either TFA or a fuel acid (= an acid that, after its deprotonation and concomitant decarboxylation, recaptures the proton ${ }^{6}$ ), NetState-II is formed, which involves

Center of Micro and Nanochemistry and (Bio)Technology, Organische Chemie I,

Universität Siegen, Adolf-Reichwein-Str. 2, Siegen D-57068, Germany.

E-mail: schmittel@chemie.uni-siegen.de; Tel: +49(0) 2717404356

$\dagger$ Electronic supplementary information (ESI) available: Experimental procedures, compound characterisations, spectral data, UV-vis titrations data. See DOI: $10.1039 / \mathrm{d} 1 \mathrm{cc} 06398 \mathrm{~g}$

\$ Isa Valiyev and Amit Ghosh contributed equally. the protonated cyclam $\mathbf{1} \cdot \mathrm{H}^{+}$and the complex $[\operatorname{Ag}(2)]^{+}$. It is revealed that both species in NetState-II are catalytically active, whereas there is no catalysis operating in NetState-I.

Ligand 1 was readily synthesised from 9-(bromomethyl) anthracene and cyclam by a substitution reaction, whereas ligand 2 was available from former work. $^{13}$ The cyclamappended ligand 1 has been selected because it binds $\mathrm{Ag}^{+}$ $(\log K=8.43 \pm 0.41$; ESI, $\dagger$ Fig. S34) much stronger than ligand $2(\log K=3.66 \pm 0.29){ }^{15}$

As foreseen, after addition of silver(I) to a mixture of ligands 1 and 2, an incomplete self-sorting was observed leading to $[\operatorname{Ag}(\mathbf{1})]^{+}+2$ denoted here as NetState-I. Upon addition of 1 equiv. of TFA to NetState-I, the ${ }^{1} \mathrm{H}-\mathrm{NMR}$, (Fig. 1) showed complete translocation of $\mathrm{Ag}^{+}$from $[\mathrm{Ag}(\mathbf{1})]^{+}$to luminophore 2 . Signals of protons $\mathrm{a}-\mathrm{H}, \mathrm{b}-\mathrm{H}$, and $\mathrm{f}-\mathrm{H}$ of $[\mathrm{Ag}(\mathbf{1})]^{+}$shifted from $8.47,8.07$, and $4.58 \mathrm{ppm}$ to $8.56,8.10$, and $4.75 \mathrm{ppm}$, respectively, confirming formation of $\mathbf{1} \cdot \mathrm{H}^{+}$. Association of $\mathrm{Ag}^{+}$to 2 was monitored by the appearance of a new peak for proton $6-\mathrm{H}$ at $7.05 \mathrm{ppm}$ as well as the disappearance of the signal at $6.70 \mathrm{ppm}$. The ESI-MS proved presence of complex $[\mathrm{Ag}(2)]^{+}$ (ESI, $\dagger$ Fig. S28) by peaks at $m / z=682.2$ (singly charged) and of $1 \cdot \mathrm{H}^{+}$by a signal at $m / z=391.5$ (singly charged) (ESI, $\dagger$ Fig. S23). Upon addition of 1 equiv. of DBU to NetState-II, a

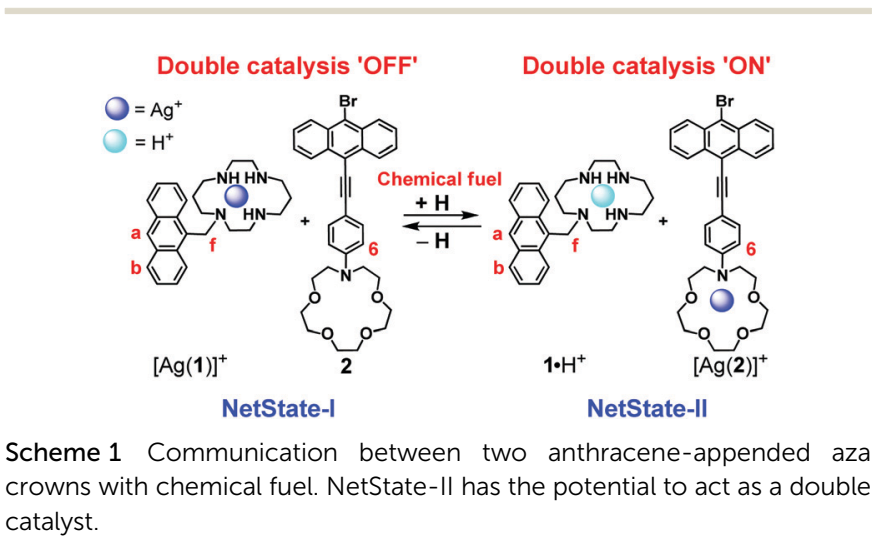




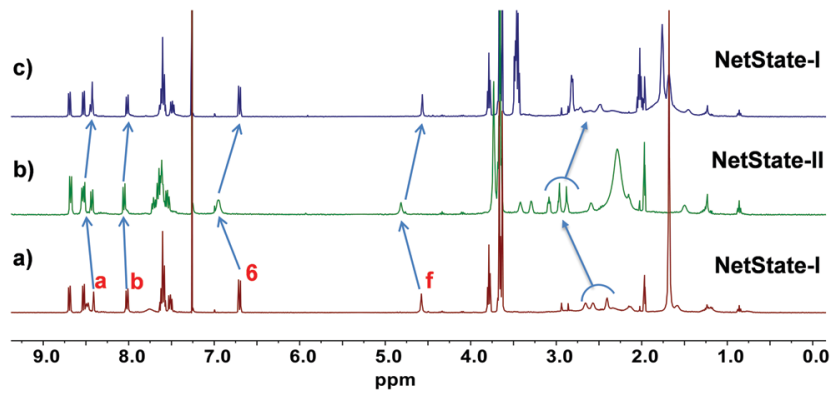

Fig. 1 Comparison of ${ }^{1} \mathrm{H}$ NMR spectra $\left(400 \mathrm{MHz}, \mathrm{CDCl}_{3}, 298 \mathrm{~K}\right.$ ) of (a) NetState-I: $[\mathrm{Ag}(\mathbf{1})]^{+}+\mathbf{2}$; (b) after addition of 1 equiv. Of TFA; (c) after addition of 1 equiv. of DBU.

clean reverse translocation of $\mathrm{Ag}^{+}$from luminophore 2 to ligand 1 was achieved.

The reversibility of the conversion of NetState-I $\leftrightarrows$ NetStateII was easily traceable by fluorescence spectroscopy, because the yellow emission of $2(\lambda=554 \mathrm{~nm})$ shifted to a pale blue $(\lambda=472 \mathrm{~nm})$, i.e. the band of $[\mathrm{Ag}(2)]^{+}$(Fig. 2a). In addition, the intensity of the emission of 1 at $\lambda=420 \mathrm{~nm}$ increased 5 -fold due to protonation. After the addition of DBU, the emission reversed back to $\lambda=554 \mathrm{~nm}$. The emission changes between the two states were reproduced over three cycles (Fig. 2b) with a small decline in emission intensity, most likely due to the formation of protonated DBU.

To probe the fuel-driven interconversion of $[\operatorname{Ag}(\mathbf{1})]^{+}+2 \leftrightarrows \mathbf{1}$. $\mathrm{H}^{+}+[\mathrm{Ag}(2)]^{+}$, an equimolar amount of 2-cyano-2-(4-methoxyphenyl)propanoic acid (3) ${ }^{16}$ was added to NetState-I. As elaborated by Di Stefano, acid 3 behaves as a chemical fuel because after deprotonation and concomitant decarboxylation of 4 the resultant anion 5 acts as a strong base thus reclaiming protons from the system to form 6 (Scheme 2).

For running the fuelled translocation, ligands $1(c=3.98 \times$ $\left.10^{-3} \mathrm{M}\right), 2$ and silver(I) ions $(1: 1: 1)$ were mixed in $450 \mu \mathrm{L}$ of $\mathrm{CD}_{2} \mathrm{Cl}_{2}$, then an equimolar amount of acid 3 was added. The disappearance of the ${ }^{1} \mathrm{H}$ NMR signals at 7.46 and $6.85 \mathrm{ppm}$ and the appearing peaks at 7.28 and $6.91 \mathrm{ppm}$ are indicative of the conversion of 3 to 6 . Five minutes after addition of 3 , the ${ }^{1} \mathrm{H}$ NMR spectrum showed full conversion of NetState-I to NetState-II (ESI, $\uparrow$ Fig. S33). For instance, the signals of protons
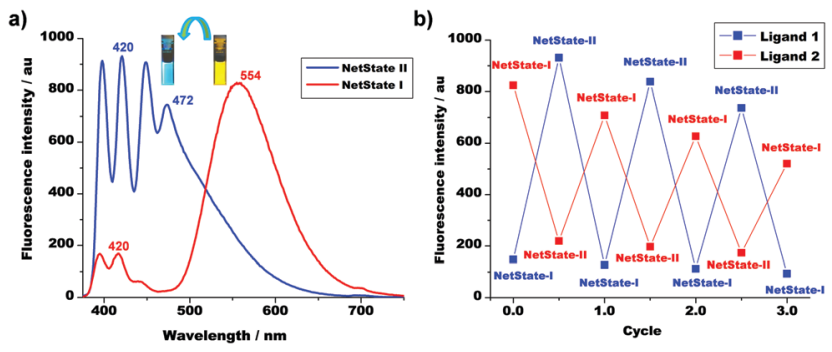

Fig. 2 (a) Emission changes after addition of TFA to $[\mathrm{Ag}(\mathbf{1})]^{+}+2$ (c $=$ $7.69 \times 10^{-6} \mathrm{M}$ ). (b) Reversibility of the networked system in presence of TFA and DBU over three cycles monitored by fluorescence. Blue and red lines indicate the changes of fluorescence intensity of ligands $\mathbf{1}$ and $\mathbf{2}$ at $\lambda=420$ and $554 \mathrm{~nm}$, respectively.

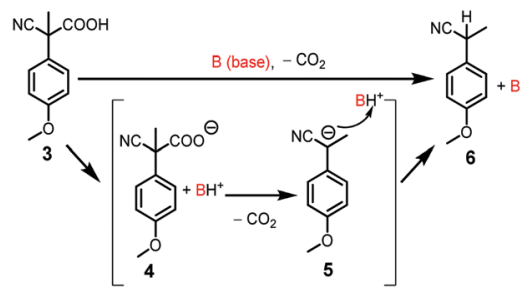

Scheme 2 The decarboxylation pathway of fuel $\mathbf{3}$ in presence of a base.

$\mathrm{f}-\mathrm{H}$ of $[\mathrm{Ag}(\mathbf{1})]^{+}$and of $6-\mathrm{H}$ of ligand 2 shifted from 4.58 to $4.75 \mathrm{ppm}$ and from 6.70 to $7.05 \mathrm{ppm}$, respectively. Over the ensuing $120 \mathrm{~min}$, complete disappearance of the ${ }^{1} \mathrm{H}-\mathrm{NMR}$ signals of NetState-II and return of the system back to NetState-I was monitored by the diagnostic peaks of $1 \cdot \mathrm{H}^{+}$at $4.75 \mathrm{ppm}$ and of waste 6 at $6.91 \mathrm{ppm}$. The time dependence of the fuel-driven transformation was also followed by fluorescence (Fig. 3a). After the addition of one equiv. of fuel $3(c=$ $1.54 \times 10^{-3} \mathrm{M}$ ) to NetState-I (i.e. $1: 2: \mathrm{Ag}^{+}=1: 1: 1$ ratio) at room temperature, the emission of 2 shifted within the first minute from $\lambda=554$ to $472 \mathrm{~nm}$. Thus, protonation of $[\operatorname{Ag}(\mathbf{1})]^{+}$by acid 3 apparently culminated in the pulsed formation of $[\mathrm{Ag}(2)]^{+}$. Simultaneously, the fluorescence intensity at $\lambda=$ $420 \mathrm{~nm}$ increased by 4.5 -fold due to the conversion of $[\operatorname{Ag}(1)]^{+}$ to $\mathbf{1} \cdot \mathrm{H}^{+}$. After decarboxylation of $\mathbf{4}$ and deprotonation of $1 \cdot \mathrm{H}^{+}$by 5, full back translocation of $\mathrm{Ag}^{+}$was detected by the emission shifting back to the original position within ca. $140 \mathrm{~min}$ (Fig. 3a). In the course of three repetitive fuelled cycles, each started by the addition of 1 equiv. of acid 3, a sawtooth profile of $\mathbf{1} \cdot \mathrm{H}^{+}$was generated (Fig. 3b). As seen from the fluorescence, the intensity spiked after each fuel addition and then dropped slowly. With each cycle, the reversal to NetState-I slightly increased in time (140 vs. 150 and $158 \mathrm{~min}$ ). Moreover, the relative top level of the emission slightly decreased, most probably owing to the formation of fuel waste $\mathbf{6}$ that acted as quencher (ESI, $\dagger$ Fig. S35 and Scheme 2).

Based on former work, we expected silver(I) to be active in catalysis when it is coordinated to the azacrown unit as in $[\mathrm{Ag}(\mathbf{2})]^{+},{ }^{15}$ but importantly $[\mathrm{Ag}(\mathbf{1})]^{+}$should be catalytically inactive. After a screening of possible reactions, we found that $[\mathrm{Ag}(2)]^{+}(10 \mathrm{~mol} \%)$ catalysed the cyclisation of substrate 10 (100 $\mathrm{mol} \%$ ) in $\mathrm{CD}_{2} \mathrm{Cl}_{2}: \mathrm{CD}_{3} \mathrm{CN}=50: 1$ (at room temp. within

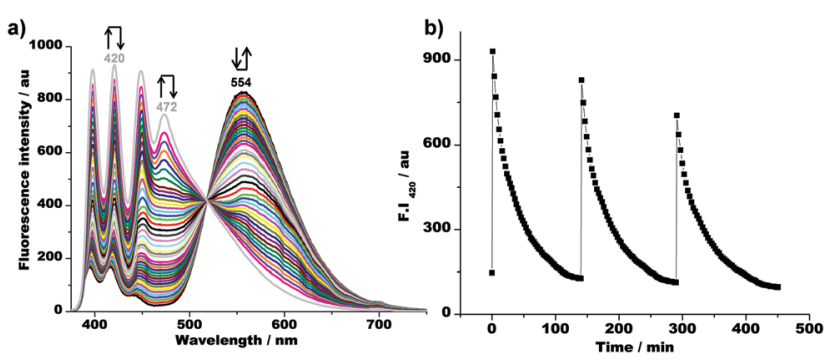

Fig. 3 (a) Communication between both NetStates after addition of fuel monitored by fluorescence $\left(c=7.69 \times 10^{-6} \mathrm{M}\right.$ ). (b) Reversibility of the chemical network in presence of fuel over three cycles monitored by fluorescence intensity at $\lambda=420 \mathrm{~nm}$. 


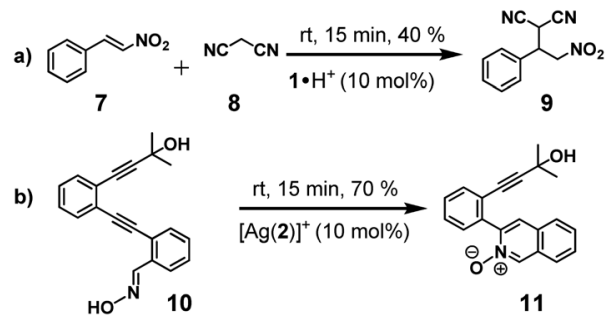

Scheme 3 The two catalytic reactions used in this work. (a) Michael addition; (b) cyclisation reaction.

$15 \mathrm{~min}$ ) affording the isoquinoline-2-oxide $\mathbf{1 1}$ in $(70 \pm 2) \%$ (Scheme $3 \mathrm{~b}$ ), whereas in presence of $[\operatorname{Ag}(\mathbf{1})]^{+}, \mathbf{2}$, or $\mathbf{1} \cdot \mathrm{H}^{+}$ (10 mol\%) formation of $\mathbf{1 1}$ was completely off. Less expected was the fact that protonated cyclam $1 \cdot \mathrm{H}^{+}$proved active in a base-catalysed Michael addition. Rewardingly, when substrates 7 and 8 (100 mol\%) were reacted with $1 \cdot \mathrm{H}^{+}(10 \mathrm{~mol} \%)$ in $\mathrm{CD}_{2} \mathrm{Cl}_{2}: \mathrm{CD}_{3} \mathrm{CN}=50: 1$ at room temp. for $15 \mathrm{~min}$, the substituted malononitrile 9 formed in $(40 \pm 2) \%$ (Scheme $3 \mathrm{a})$. In contrast, the Michael addition did not proceed in presence of 2, $[\operatorname{Ag}(2)]^{+}$or $[\operatorname{Ag}(\mathbf{1})]^{+}(10 \mathrm{~mol} \%)$ as potential catalysts. ${ }^{17}$

The surprising catalysis of the Michael addition by $1 \cdot \mathrm{H}^{+}$ might in principle be alternatively explained by the intermediate formation of the ketenimine $\mathrm{NC}-\mathrm{CH}=\mathrm{C}=\mathrm{NH}$, i.e. the "enol tautomer" of $\mathbf{8}$, and thus an acid catalysed reaction. To examine the possible involvement of acid catalysis we tested the reaction of compounds 7 and 8 (1:1 ratio, in $\mathrm{CD}_{2} \mathrm{Cl}_{2}, 2 \mathrm{~h}$, room temp.) in presence of various acids. Neither acid 3 nor TFA nor higher protonated states of cyclam 1 (Fig. 4) were active in the catalysis. Moreover, we were able to demonstrate that erratically formed spurious amounts of cyclam 1 were unable to exist in presence of $[\operatorname{Ag}(2)]^{+}$because any free 1 immediately afforded $[\mathrm{Ag}(\mathbf{1})]^{+}\left(\mathrm{ESI}, \dagger\right.$ Page S47 and S48). In sum, we conclude that $1 \cdot \mathrm{H}^{+}$ despite carrying a proton, uses some of the remaining basic sites for a base catalysed Michael addition.

After successfully identifying the catalytic activity of $\mathbf{1} \cdot \mathrm{H}^{+}$ and $[\mathrm{Ag}(2)]^{+}$, both catalytic processes were studied in the networked system. Firstly, ligands 1, 2, and silver(I) were mixed in $450 \mu \mathrm{L}$ of $\mathrm{CD}_{2} \mathrm{Cl}_{2}$ in a $1: 1: 1$ ratio in order to obtain NetStateI, then 10 equiv. of reactants $7, \mathbf{8}$, and 10 were added.

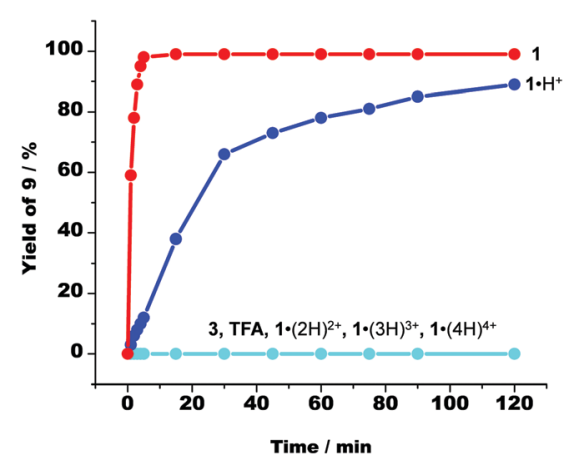

Fig. 4 The time-dependent formation of Michael addition product 9 in presence of a variety of acids and of cyclam 1. 1. $(2 \mathrm{H})^{2+}, 1 \cdot(3 \mathrm{H})^{3+}$ and 1 . $(4 \mathrm{H})^{4+}$ represent the multiply protonated cyclam 1.

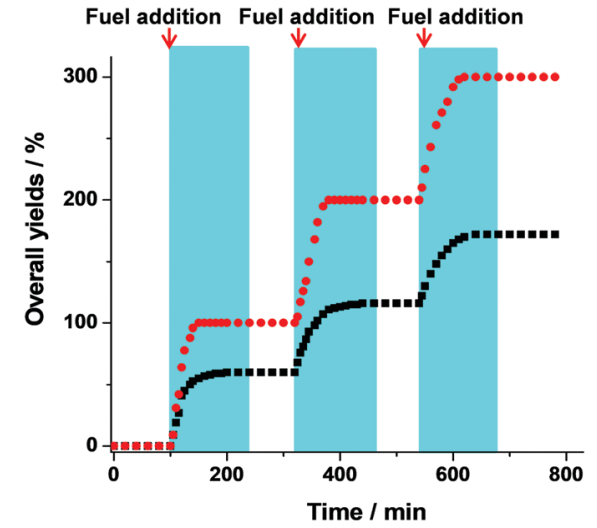

Fig. 5 Time dependence of product formation in presence of fuel 3 monitored by ${ }^{1} \mathrm{H}$ NMR spectroscopy $\left(\mathrm{CD}_{2} \mathrm{Cl}_{2}, 298 \mathrm{~K}\right)$ with 1,3,5trimethoxybenzene as an internal reference. Black and red dots represent formation of $\mathbf{9}$ and $\mathbf{1 1}$, respectively.

As expected, both the Michael addition and oxime cyclisation were shut down (OFF). The reactions are OFF, because silver(I) ions in $[\operatorname{Ag}(\mathbf{1})]^{+}$are catalytically inactive and there is no free reactive $\mathrm{NH}$ unit available. After the addition of 1 equiv. of TFA to NetState-I, NetState-II was furnished with both complexes being in the catalytically active state. Remarkably, yields of both the Michael addition and the oxime cyclisation in NetState-II were close to those of the individual experiments. For instance, after $15 \mathrm{~min}$, the cyclisation furnished $69( \pm 2) \%$ of product 11, monitored by a new peak at $8.86 \mathrm{ppm}$ (singlet) in the ${ }^{1} \mathrm{H}-\mathrm{NMR}$ spectrum, whereas the Michael addition yielded $38( \pm 2) \%$ of product 9 as indicated by a multiplet at 5.06-4.93, a doublet at 4.47, and a multiplet at 4.17-4.10 ppm.

To examine the catalytic activity of both states in presence of chemical fuel over several cycles (Fig. 5), we started with $10 \mathrm{~mol} \%$ of NetState-I and $100 \mathrm{~mol} \%$ of reactants 7,8 , and 10. The mixture was first monitored by ${ }^{1} \mathrm{H}$-NMR spectroscopy at room temperature for $100 \mathrm{~min}$, but no product formation was detected. After the addition of 3 (10 mol\%), the system turned to NetState-II delivering $9 \%$ of both $\mathbf{9}$ and $\mathbf{1 1}$ after $5 \mathrm{~min}$. After $10 \mathrm{~min}$, the yields of 9 and 11, i.e. the Michael addition and cyclisation, were increased to $19 \%$ and $31 \%$, respectively. After $20 \mathrm{~min}$ the speed of both processes decreased since some amount of chemical fuel had converted to 6; at this time $41 \%$ of 9 and 64\% of product 11 had formed. Finally, after $50 \mathrm{~min}$, the Michael addition and the cyclisation furnished $55 \%$ and $>$ 99\% yield, respectively. After $120 \mathrm{~min}$, with all the fuel 3 being consumed, the system reversed to NetState-I and the Michael addition reaction showed a yield of $60 \%$. For another fuelled cycle, the consumed amounts of reactants were supplemented. Monitoring for another $100 \mathrm{~min}$ at r.t. by ${ }^{1} \mathrm{H}$-NMR spectroscopy demonstrated the system to be completely in the OFF mode. In the second cycle, products 9 and 11 were obtained in 57\% and $>99 \%$ yield respectively. A small decrease in the yield of $\mathbf{9}$ $(60 \% \rightarrow 57 \% \rightarrow 52 \%)$ was observed over three cycles.

In conclusion, we demonstrated a switchable multicomponent network for double catalysis that was based on the fully 
reversible communication between two anthracene-appended azacrowns via translocation of $\mathrm{Ag}$ (I) ions, a process requiring a high level of self-sorting. ${ }^{18}$ Interconversion between NetState-I and NetState-II was realised by addition of stoichiometric amounts of acid and base or alternatively of chemical fuel acid (over three cycles). The use of chemical fuel 3 allowed simultaneous triggering of two orthogonal reactions under dissipative conditions. Notably, acid addition led to both base and silver(I) catalysis in concert.

This paper is dedicated to Prof. Dr A. Maercker on the occasion of his 90th birthday. We are indebted to the Deutsche Forschungsgemeinschaft (Schm 647/22-1) for financial support.

\section{Conflicts of interest}

There are no conflicts to declare.

\section{Notes and references}

1 U. Pischel, J. Andréasson, D. Gust and V. F. Pais, Information processing with molecules - Quo vadis?, ChemPhysChem, 2013, 14, 28-46.

2 C. J. Bashor, N. Patel, S. Choubey, A. Beyzavi, J. Kondev, J. J. Collins and A. S. Khalil, Complex signal processing in synthetic gene circuits using cooperative regulatory assemblies, Science, 2019, 364, 593-597.

3 A. I. Brown and D. A. Sivak, Theory of Nonequilibrium Free Energy Transduction by Molecular Machines, Chem. Rev., 2020, 120, 434-459.

4 R. Merindol and A. Walther, Materials learning from life, Chem. Soc. Rev., 2017, 46, 5588-5619.

5 M. A. Cardona, R. Chen, S. Maiti, I. Fortunati, C. Ferrante, L. Gabrielli, K. Das and L. J. Prins, Time-gated fluorescence signalling under dissipative conditions, Chem. Commun., 2020, 56, 13979-13982.

6 C. Biagini and S. Di, Stefano, Abiotic Chemical Fuels for the Operation of Molecular Machines, Angew. Chem., Int. Ed., 2020, 59, 8344-8354.

7 K. Das, L. Gabrielli and L. J. Prins, Chemically Fueled Self-Assembly in Biology and Chemistry, Angew. Chem., Int. Ed., 2021, 60, 20120-20143.
8 L. S. Kariyawasam, M. M. Hossain and C. S. Hartley, The Transient Covalent Bond in Abiotic Nonequilibrium Systems, Angew. Chem., Int. Ed., 2021, 60, 12648-12658.

9 O. R. Maguire, A. S. Y. Wong, J. H. Westerdiep and W. T. S. Huck, Early warning signals in chemical reaction networks, Chem. Commun., 2020, 56, 3725-3728.

10 (a) A. Goswami, S. Saha, P. Biswas and M. Schmittel, (Nano)mechanical Motion Triggered by Metal Coordination: from Functional Devices to Networked Multicomponent Catalytic Machinery, Chem. Rev., 2020, 120, 125-199; (b) M. Schmittel, Dynamic Functional Molecular Systems: from Supramolecular Structures to Multicomponent Machinery and to Molecular Cybernetics, Isr. J. Chem., 2019, 59, 197-208.

11 C. Biagini, S. D. P. Fielden, D. A. Leigh, F. Schaufelberger, S. Di Stefano and D. Thomas, Dissipative Catalysis with a Molecular Machine, Angew. Chem., Int. Ed., 2019, 58, 9876-9880.

12 B. A. Grzybowski and W. T. S. Huck, The Nanotechnology of Lifeinspired Systems, Nat. Nanotechnol., 2016, 11, 585-592.

13 A. Ghosh, I. Paul and M. Schmittel, Time-Dependent Pulses of Lithium Ions in Cascaded Signaling and Out-of-Equilibrium (Supra)molecular Logic, J. Am. Chem. Soc., 2019, 141, 18954-18957.

14 (a) Z. He, W. Jiang and C. A. Schalley, Integrative self-sorting: a versatile strategy for the construction of complex supramolecular architecture, Chem. Soc. Rev., 2015, 44, 779-789; (b) M. L. Saha and M. Schmittel, Degree of molecular self-sorting in multicomponent systems, Org. Biomol. Chem., 2012, 10, 4651-4684; (c) W. Jiang and C. A. Schalley, Integrative self-sorting is a programming language for high level self-assembly, Proc. Natl. Acad. Sci. U. S. A., 2009, 106, 10425-10429.

15 I. Paul, N. Mittal, S. De, M. Bolte and M. Schmittel, Catch-Release System for Dosing and Recycling Silver(I) Catalyst with Status of Catalytic Activity Reported by Fluorescence, J. Am. Chem. Soc., 2019, 141, 5139-5143.

16 C. Biagini, S. Albano, R. Caruso, L. Mandolini, J. A. Berrocal and S. Di, Stefano, Variations in the fuel structure control the rate of the back and forth motions of a chemically fueled molecular switch, Chem. Sci., 2018, 9, 181-188.

17 (a) R. Singha and T. Goswami, Acid catalyzed 1,2 Michael addition reaction: a viable synthetic route in designing fullerene core starlike macromolecule, J. Phys. Org. Chem., 2008, 21, 225-236; (b) T. C. Wabnitz and J. B. A. Spencer, General, Brønsted AcidCatalyzed Hetero-Michael Addition of Nitrogen, Oxygen, and Sulfur Nucleophiles, Org. Lett., 2003, 5, 2141-2144.

18 M. Schmittel, From self-sorted coordination libraries to networking nanoswitches for catalysis, Chem. Commun., 2015, 51, 14956-14968. 